\title{
RETROGRESSIVE CONSEQUENCES OF CIGARETTE SMOKING ON SERUM LIVER FUNCTION ENZYMES ACTIVITIES AND ANTIOXIDANTS STATUS AMONG SMOKERS
}

\author{
Mariama Salihu \\ Department of Biochemistry, \\ Faculty of Biomedical Sciences, \\ Kampala International University, Uganda
}

\begin{abstract}
Cigarette smoke contain large amount of oxidants which are capable of generating reactive species which play key role in oxidative stress. This study estimated the effects of cigarette smoking on serum antioxidant status and lipid peroxidation between smokers and non-smokers. Twenty healthy $(n=10)$ smokers (consume at least 5 sticks of cigarette per day) and non-smokers (never smoke in life) aged 15 - 35 years were recruited for the research. Serum antioxidant vitamins (A, C, and E), ALP, ALT and malondialdehyde were estimated and compared to aged matched control (non-smokers) group. The levels of all those antioxidant vitamins were found to be significantly lower $(\mathrm{P}<0.05)$ in smokers than nonsmokers, ALT and ALP activities and malondialdehyde level were found to be significantly higher $(\mathrm{P}>0.05)$ in smokers than non-smokers. It could therefore be concluded that even while looking healthy, cigarette smoking increase the rate of possible exposure to all adverse life shortening diseases as a result of depletion of antioxidants to scavenge the excess free radicals consumed in cigarette smoking.
\end{abstract}

KEYWORDS: Cigarette; Antioxidants; Lipid Peroxidation; Smokers; Serum.

\section{INTRODUCTION}

The world health organization (WHO) in 2002 ranked tobacco smoking among the ten greatest factors of death and manifestation of many chronic diseases. It has been estimated that 1 billion men and
50 million women currently smoke cigarettes, a possible major risk factor for cancer, heart, lung diseases, cancer, cardiovascular diseases, diabetes, Alzheimer's disease, Parkinson's disease, and visual disease such as cataract and age-related muscular degeneration (Gandhi et al., 2009; Thum, 2013).

Cigarette is a product consumed through inhalation of smoke and manufactured from cured and finely cut tobacco leaves and reconstituted tobacco, often combined with other additives, then rolled into a paper cylinder (Maod and Solom, 1995). Nicotine is the main active ingredient of tobacco. In 1851, the Belgium chemist Jean Stas documented the use of tobacco extract as "murder poison" (Johnson et al., 1997). Cigarette is a mixture of 4000 bioactive substances (nicotine, hydrogen cyanide, methanol, butane, etc) which are capable of causing an increase in the generation of various reactive oxygen species (ROS), reactive nitrogen species (RNS) and also acetaldehyde, which are collectively called "free radicals", they undergo complex interaction with human biological system (Heinecke et al., 1994; Chappel et al., 1997; Henderson et al., 1999; Iain et al., 2007; Kim et al., 2007). It has been reported that one puff of cigarette exposes the smoker to more than $10^{15}$ free radicals and other oxidants (Pryor and stone, 1993). It is also attributed to about $23 \%$ of all coronary heart disease deaths and also to other heart related diseases including hypertension, Ischemic heart disease and atherosclerosis among. It may reduce fertility, and is a known cause of erectile dysfunction in men (Gades et al., 2005). Research studies have found that smoking and exposure to 
International Journal of Engineering Applied Sciences and Technology, 2019

Vol. 4, Issue 6, ISSN No. 2455-2143, Pages 240-248

Published Online October 2019 in IJEAST (http://www.ijeast.com)

second hand smoke pregnant women are major causes of spontaneous abortions, stillbirths and sudden infant deaths syndrome (Armstrong, 1992). Similarly, it causes ectopic pregnancy, a condition that is very rarely survivable for the fetus and is potentially fatal for the mother (Jackshaw et al., 2011). Children exposed to secondhand smoke before and after birth are at great risk of abnormal blood pressure, cleft palates, and lips, childhood leukemia, attention deficit disorder, childhood wheezing, and respiratory disorders (Ahlborg and Bondin,.., 1991; Cooke, 1991). In 2010, approximately 5 million died each year from tobacco related illnesses and if current trends continue, this figure will rise to about 10 million by 2025 .

The defense system against radicals consists of enzymatic and non-enzymatic; essential and nonessential; endogenous and exogenous free radicals scavengers which may possess a protective role and may reduce the incidence of major diseases associated with cigarette smoking (Eduardu et al., 1999). This research compared serum antioxidant status, liver function indices and lipid peroxidation in cigarette smokers and non- smokers. The specific objectives end point of this research are to determine anthropometric parameters such as body weight, height, hip width; hematological study, serum levels of antioxidants vitamin (A, C and E), serum activities ALT and ALP on the cigarette smokers and nonsmokers.

\section{MATERIAL AND METHODS}

Sample Collection, Separation and Storage: Twenty healthy volunteers from the community were recruited after collection of their respective data using questionnaire and their serum was used in the study. Blood samples were drawn after an overnight fasting and allowed to coagulate. The coagulated blood was centrifuged to separate the serum from the whole blood at 4000 revolution per minute (rpm) for 5 minutes. The supernatant was pipette into plain bottles and stored at $0{ }^{\circ} \mathrm{C}$ until required for analysis.

Determination of Serum Parameters: Estimation of serum vitamin A by Latimer (2007) methods while serum vitamin C was by Baker and Frank (1968) method with the ascorbic acid oxidizes to dehydroascorbic acid, which is an acid solution reacts with 2, 4-dinitrophenylhydrazine (DNPH) forming a corresponding hydrazone. The hydrazone when reacted with sulfuric acid $\left(\mathrm{H}_{2} \mathrm{SO}_{4}\right)$ develops an orange-red color, which is measured spectrophotometrically at $520 \mathrm{~nm}$. Estimation of serum vitamin E by Baker and Frank (1968) method based on the reduction of ferric ions to ferrous ions which forms red color which diphyridyl acid then measured spectrophotometrically at $460 \mathrm{~nm}$. Estimation of serum malondialdehyde was by Hartman (1983) method whereby malondialdehyde in serum reacts with thiobarbutric acid (TBA) in acidic medium that produces a pink color complex which is measured spectrophotometrically at $532 \mathrm{~nm}$.

\section{STATISTICAL ANALYSIS}

Results are presented as means \pm standard error of the mean (SEM). The parameters were analysed statistically using student's t-test and One-way Analysis of Variance (ANOVA) with GraphPad instat software; version 3.1 and Microsoft excel; 2010 version. Difference were considered statistically significant at $\mathrm{P}<0.05$.

\section{RESULTS}

\section{Anthropometric Parameters of Smokers and Non- Smokers}

The effect of anthropometric parameters such as weight, height, hip size, body mass index, biceps of smokers were compared with that of non-smokers (Figure 1, 2 and 3). There was no significant difference $(\mathrm{P}>0.05)$ when compared with the control (non- smokers). 
International Journal of Engineering Applied Sciences and Technology, 2019

Vol. 4, Issue 6, ISSN No. 2455-2143, Pages 240-248

Published Online October 2019 in IJEAST (http://www.ijeast.com)

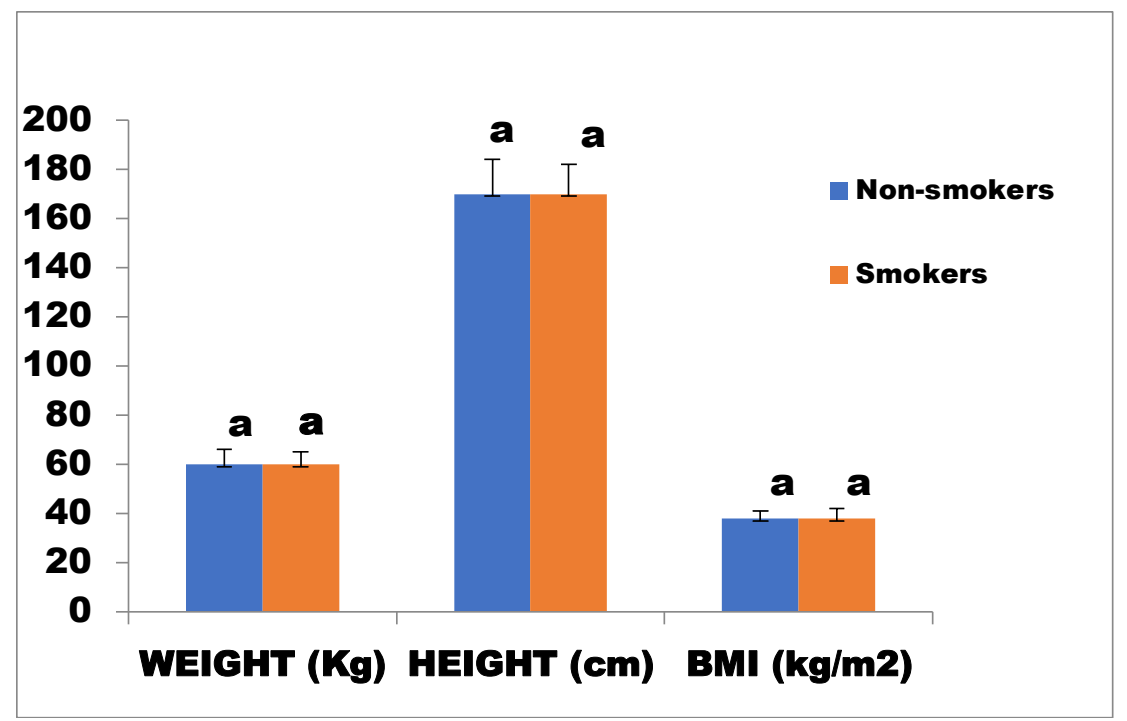

Figure 1: Effect of Cigarette Smoking on Body Weight, Height and Body Mass Index (BMI) of Smokers and Non-Smokers

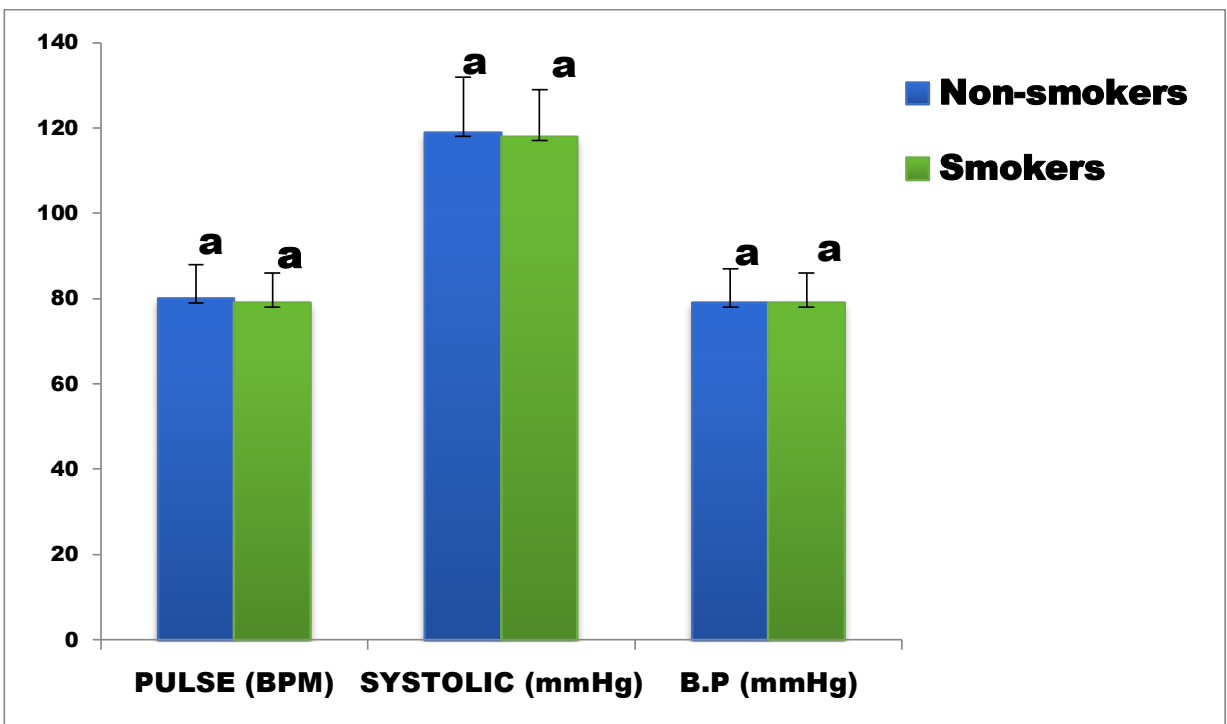

Figure 2: Effect of Cigarette Smoking on Pulse, Systolic and Diastolic Pressure of Smokers and Non-Smokers 


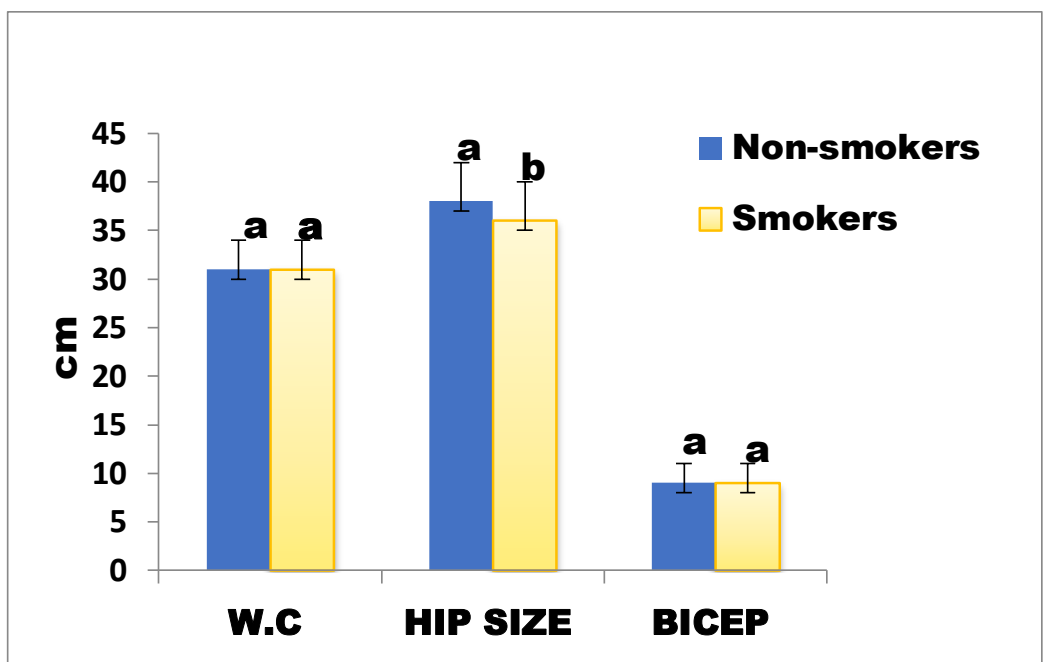

Figure 3: Effect of Cigarette Smoking on Waist Circumference (W.C), Hip Size, and Bicep of Smokers and Non-Smokers

Serum Antioxidant Vitamins Levels in Smokers and Non-Smokers
Figure 4 shows serum antioxidant vitamins (A, C, and E) levels in smokers and non-smokers. It has proven that cigarette smoking significantly decreased $(\mathrm{P}<0.05)$ the level of antioxidant vitamins.

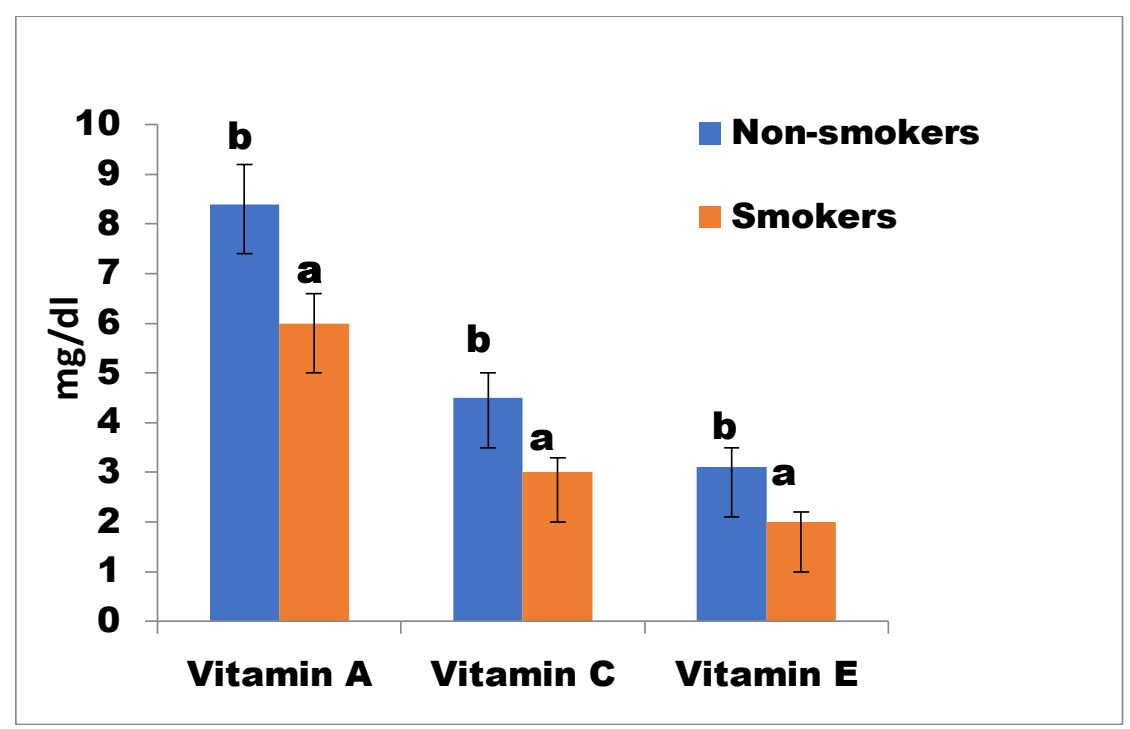

Figure 4: Serum Antioxidant Vitamins A, C and E Levels in Smokers and Non-Smokers

Liver function Enzymes Activities in Smokers and Non-Smokers

Figure 5 shows the liver function activities of ALT and ALP enzymes between smokers and non- smokers. It was observed that smokers have significant higher $(\mathrm{P}>0.05)$ liver function enzymes ALP and ALT activities when compared with nonsmokers. 
International Journal of Engineering Applied Sciences and Technology, 2019

Vol. 4, Issue 6, ISSN No. 2455-2143, Pages 240-248

Published Online October 2019 in IJEAST (http://www.ijeast.com)
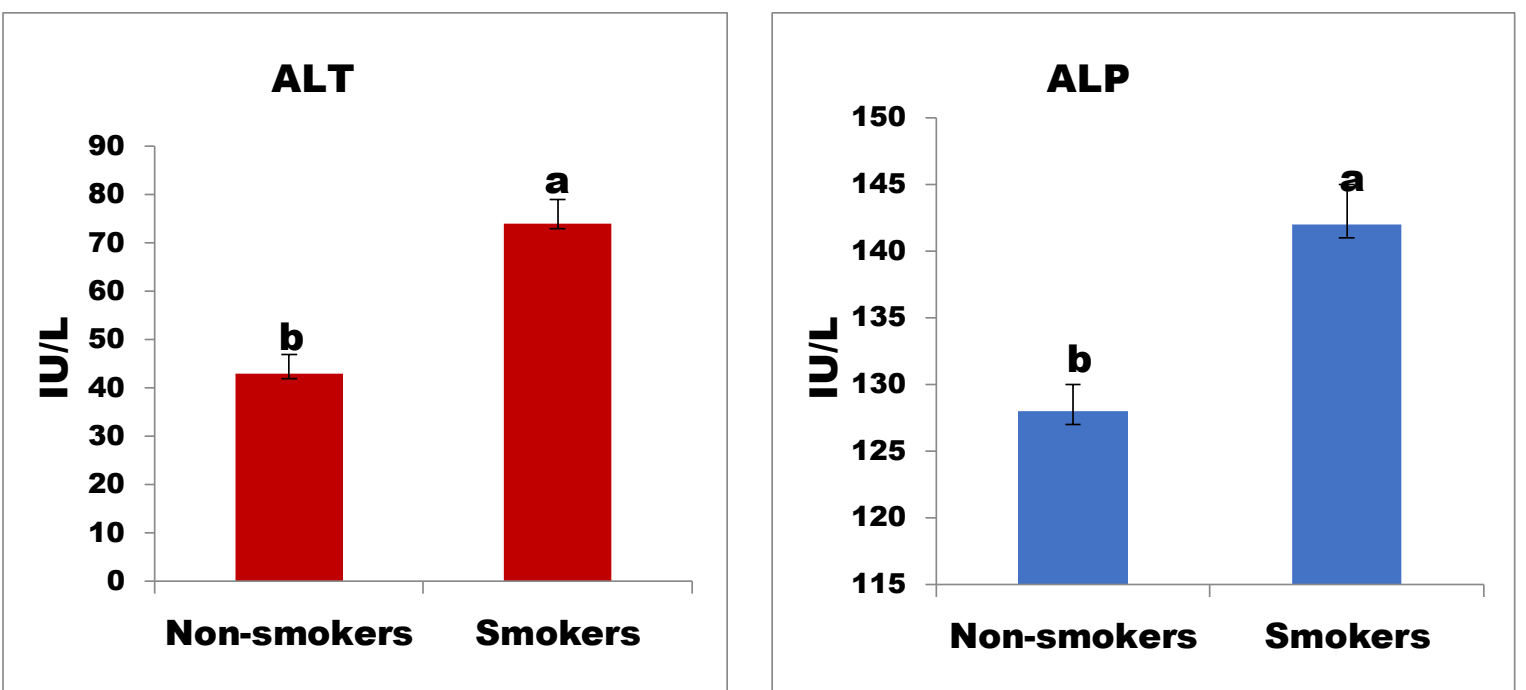

Figure 5: Effects of Cigarette Smoking on Serum Alanine Transaminase (ALT) and Alkaline Phosphatase (ALP) Activities in Smokers and Non-Smokers

Serum Level of Malondialdehyde in Smokers and Non-Smokers

The effect of cigarette smoking on MDA level was compared with the control (non-smokers). Figure 6 shows MDA level between smokers and nonsmokers. It reveals that smokers have higher level of MDA compared to non-smokers and this will finally lead to lipid peroxidation

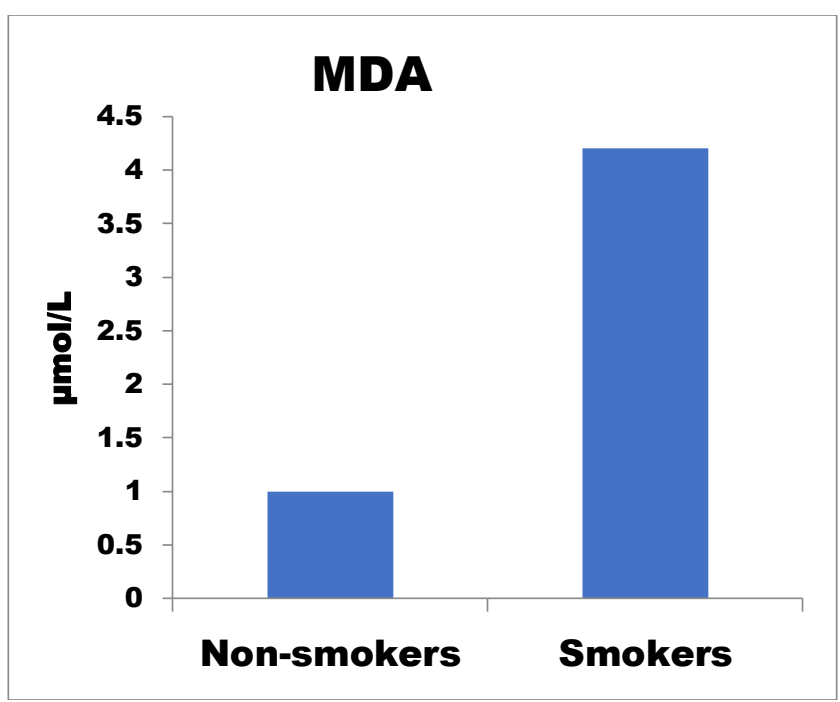

Figure 6: Effects of Cigarette Smoking on Serum Level of Malondialdehyde in Smokers and Non-Smokers

Hematological Profiles of Smokers and Non-Smokers

Table 1: Hematological of Smokers and Non-Smokers

\begin{tabular}{|l|l|l|}
\hline Parameters & Smokers & Non-Smokers \\
\hline
\end{tabular}


International Journal of Engineering Applied Sciences and Technology, 2019

Vol. 4, Issue 6, ISSN No. 2455-2143, Pages 240-248

Published Online October 2019 in IJEAST (http://www.ijeast.com)

\begin{tabular}{|l|l|l|}
\hline PVC & $35 \pm 1.1$ & $29.2 \pm 0.75$ \\
\hline RBC $\left(\mathbf{1 0}^{3} \boldsymbol{\mu L}\right)$ & $3.24 \pm 0.87$ & $3.06 \pm 0.59$ \\
\hline WBC $\left(\mathbf{1 0}^{\mathbf{3}} \boldsymbol{\mu L}\right)$ & $4.211 \pm 0.12$ & $3.70 \pm 0.05$ \\
\hline Hb $(\mathbf{g} / \mathbf{d l})$ & $14.01 \pm 2.23$ & $12.71 \pm 1.23$ \\
\hline PLT $\left(\mathbf{1 0}^{\mathbf{3}} \boldsymbol{\mu L}\right)$ & $152.25 \pm 50.25$ & $170 \pm 40.13$ \\
\hline MPV $(\mathbf{f l})$ & $3.26 \pm 1.10$ & $3.28 \pm 0.74$ \\
\hline
\end{tabular}

KEY USED: Packed cell volume (PCV), Red Blood Cell (RBC), White Blood Cell (WBC), Hemoglobin (Hb), Platelet (PLT), and Mean Platelet Volume (MPV)

\section{DISCUSSION}

Cigarette smoking has been report to contain larger amount of free radicals and other highly reactive molecules. The increase concentration of the reactive molecules in tissue could induce lipid peroxidation. With contaminant release of products such as malondialdehyde which can be assayed as a marker (Morrow et al., 1995; Abdulrahman et al., 1997; Flemming et al.,1997; Reejomol and Swaminathan, 2013). Similarly, this study is aligned to the above findings; revealing that the concentration of malondialdehyde was found to be higher in smoker than non-smokers. The observed increase in the level o malondialdehyde in the serum of the smokers is linked to the increase in the level of exogenous free radicals generated from the cigarette smoke that ultimately lead to lipid peroxidation (Reejomol and

Swaminathan, 2013). It is suggested cigarette smoke impair the oxidant-anti oxidant balance, which is a major risk factor in oxidative stress (Hauwa'u et al., 2017).

Vitamin A is a strong antioxidant and is the best quencher of singlet oxygen. Its lipophilic nature allows it to pass across the membrane and scavenge free radicals (Eiserich et al., 1995; Wallstrom et al., 2000). Diverse observation were reported on the effect of cigarette smoking and serum levels of vitamin A. some revealed a significant effect (Parviannen et al., 2009; Antwerpen et al., 1995; Ascherio et al., 1992; Wallstrom et al., 2000; Chui et al., 2009) while others observed a significant increase in the levels of vitamin A (Biesalski et al., 1986). Correspondingly, this research revealed that smokers had significantly lower levels of serum Vitamin A than non-smokers at $\mathrm{p}<0.05$. Even so, Ojima et al, reported that even low levels of vitamin A may inhibit lipid peroxidation and thus reduce the oxidative loss of vitamin $\mathrm{E}$ by singlet oxygen $\left({ }^{1} \mathrm{O}_{2}\right)$ (Ojima et al., 1993). Consequently, it is likely that a lower level of vitamin A among smokers in an upshot of destruction of this antioxidant during neutralization of free radicals present in cigarette smoke which contain more free radicals than the biological antioxidant defense system can handle (Abdulrahman et al., 1997). Vitamin C is a watersoluble vitamin that efficiently scavenges free radicals and inhibits lipid peroxidation. It also promotes the regeneration of the active form of vitamin $E(\alpha$ - tocopherol) from $\alpha$ - tocopheroxyl racdical produced during scavenging of ROS (Satyanarayana and Chakrapani, 2006) vitamin C levels. Some revealed there is effect; showing that smokers have statistically significant lower levels than non- smokers (Gey, 1992; Greg, 2003) while others reported a reverse effect. Previous reports have shown that low vitamin $\mathrm{C}$ concentration in the plasma/ serum, leukocytes, and urine of cigarette smokers are associated with increased number of neutrophils, which suggests increased utilization, lower intake, or reduced bioavailability of vitamin C in smokers than non-smokers (Chow, 1997). A significant amount of researches indicates that smokers may have higher requirement for vitamin $\mathrm{C}$ (Burri and Jacob, 1997) and concentration of vitamin $\mathrm{C}$ are lower in smokers than non-smokers that is inversely related to cigarette use (Cross and Halliwell, 1993). Conversely, this research indicated smokers had lower levels of serum vitamin A than non-smokers with significantly difference.

This result is evidence that accumulation of excess free radicals and other reactive molecules regenerated from cigarette smoke which depletes/reduces the level of vitamin $\mathrm{C}$ in the serum as seen in smokers (Christine et al., 2006). Among other plausible explanations, the lower serum Vitamin C levels observed in smokers might reflect an altered metabolism of ascorbic acid, decrease absorption; 


\section{International Journal of Engineering Applied Sciences and Technology, 2019 Vol. 4, Issue 6, ISSN No. 2455-2143, Pages 240-248 \\ Published Online October 2019 in IJEAST (http://www.ijeast.com)}

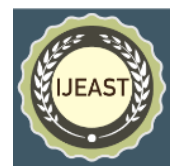

increased metabolism demand, increased elimination, or any combination of these factors might influence the metabolic fate of ascorbic acid, resulting in the consistent observation of lower serum level in the smoking population (Christine et al., 2006).

Lipid structures, like membranes are particularly susceptible to oxidative stress. Smokers have been reported to display evidence of more endogenous lipid peroxidation than non-smokers (Kelly, 2002). The biological activity of vitamin $\mathrm{E}$ is almost entirely due to its antioxidant properties. In addition to its antioxidant role, vitamin $\mathrm{E}$ might also have a structuring role in stabilizing membrane and it particular effective in preventing lipid peroxidation (Christine et al., 2006; Hauwa'u et al., 2017).

In the same way, this study shows that the serum level of vitamin $\mathrm{E}$ was observed to be significantly lower in smokers than non-smokers at $\mathrm{p}<0.05$. It is in line with the findings of other studies (Mezzetti et al., 1995; Palanisamy et al., 2009). Abdulrahman et al. (1997) also reported a similar result but there was no significance between two subject groups. The abundance of free radicals in cigarette smoke may induce oxidative stress in respiratory and circulatory systems, and the lower concentration of antioxidants found in smokers may be due to a sustained smokerelated oxidant load that depletes the antioxidant (Walmsley et al., 1994). It is now evident that the level of free radicals consumed in cigarette smokes induces lipid peroxidation and ultimately lead to decrease in vitamin E levels in the serum because it is involved in breaking the chain reaction initiated.

The observed increase and decrease levels of malondialdehyde and antioxidant vitamins respectively in smokers in relation to increase in levels of cigarette consumption in this study is evident that increase in free radicals generation, lipid peroxidation and subsequent release of MDA which decrease the levels of antioxidant vitamins in the serum as the results of their constant destruction during the neutralization of these free radicals. This is in line with findings of Christine and David (2007).

This study exposed that there was no significant difference between serum levels of antioxidant vitamins and malondialdehyde in smokers in relation to different age group. This is in contrast to the findings of Chui et al., (2009) and also Christine and David (2007). This may be due to narrowing of age range (15 to 35 years) in this research, difference in rate of cigarette consumption, duration of smoking, dietary intake of fruits and vegetables or combination of these. It has been speculated that difference are at least partly dependent on differences in dietary intake of antioxidant vitamins (Gey, 1992).
Therefore, combination of cigarette smoking and low dietary intake of essential antioxidant may aggravate the damage of oxidant present in cigarette smoke. Enzymes are leaked out into blood and increased the level of ALP and ALT in smokers when compared to non-smokers. In this study, we have observed the ALP and ALT activities were significantly increased in smoker's plasma. Although the results showed elevated ALP levels in smokers compared to nonsmokers, ALP was strongly influenced by smoking (Vardavas et al., 2012; Gboyega et al., 2013). Cigarette smoking has been found to cause several major morphological and biochemical problems in individuals. In this study, hematological parameters had been used for comparative analysis between smokers and non-smokers. The experimental results showed significant difference in hematological parameters of subject; PCV, RBC, WBC, Hb, PLT, and MPV levels.

The high WBC count may suggest they might be at great risk of developing atherosclerosis and cardiovascular diseases than non-smokers. This study shows that hemoglobin values were significantly high in smokers. Elevated level of hemoglobin is found with increased numbers or size of RBCs. RBC values was significantly high in smokers than non-smokers. It is reported that the high level of RBC and WBC are associated with blood viscosity and clotting in smokers (Levenson, 2003).

\section{CONCLUSION}

This research revealed that increase in cigarette consumption decrease the level of serum antioxidant vitamins (Vitamin $\mathrm{A}, \mathrm{C}$ and $\mathrm{E}$ ) and increase the extent of lipid peroxidation although age difference and anthropometric parameters were not found to have any significant differences between smokers and non-smokers. Heavy smoking was associated with increased ALT and ALP levels. It clearly shows that continuous cigarette smoking has severe adverse effect on hematological parameters

\section{REFERENCES}

1. Abdulrahman, M., Al-Senaidy, Y.A and AlZahrany., and Al-Faqeeh, M.B. (1997). Effect of smoking on serum levels of lipid peroxides and essential fat soluble antioxidants, Nutrition and health center, 12: (pp 55-66).

2. Ahlborg, G., Jr., and Bondin, L. (1991). Tobacco smoke exposure and pregnancy outcome among women: a prospective study at parental care 


\section{International Journal of Engineering Applied Sciences and Technology, 2019 Vol. 4, Issue 6, ISSN No. 2455-2143, Pages 240-248 \\ Published Online October 2019 in IJEAST (http://www.ijeast.com)}

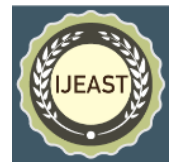

centers in Orebro country, Sweden AJE 133(4): (pp 338-347).

3. Antwerpen, V.L., Fickl, H., and Richard, G.A (1995). Increase levels of auto-antibody to cardiolipin and oxidazide low density lipoprotein are inversely associated with plasma vitamin $\mathrm{C}$ status in cigarette smokers. Atherosclerosis, 124 (pp 75-81)

4. Amstrong, B.G. (1992). Cigarette, Alcohol, and Coffee consumption and spontaneous abortion. AJPH, 82(1): (pp 85-7).

5. Ascherio, A., Stampfer, M.J., Colditz, G.A., Rimm, E.B., Litin, L., and Willett, W.C. (1992). Correction of vitamin $\mathrm{A}$ and $\mathrm{E}$ intakes with the plasma concentrations of carotenoids and tocopherols among American men and women. J. Nutr 122: (pp 1792-801).

6. Baker, H., and Frank, O. (1968). Assay of Vitamin $\mathrm{E}$ and $\mathrm{C}$ in plasma. Clinical Vitaminology, New York. Wiley, (pp 172).

7. Biesalsk, H., Greiff, H., Brodda, K., Hafner, G., and Bassler K.H. (1986). Rapid determination of vitamin A (retinol) and vitamin E ( $\alpha$-tocopherol) in human serum by isocratic adsorption HPLC. Internal. J. Vit. Nutr. Res., 56, (pp 319-327).

8. Burri, B.J., and Jacob, R.A. (1997). Human metabolism and requirements for vitamin C. In: Packer, L., Fuchs, J., editors. Vitamin $C$ in health and disease. New York: Marcel Dekker Inc; (pp 341-66).

9. Chappel, I.L.C., Mason, G.I., and Garner, I. (1997). Enhanced Chemiluminiscent assay for measuring the total antioxidant capacity of serum, saliva and cervicular fluid. Am Clin Biohem, 34(4); (pp 412-21).

10. Chow, C.K. (1997). Vitamin C and Cigarette smoke exposure. In: Packer, L., Fuchs, J., editor. Vitamin $C$ in health and disease, (pp 413-24).

11. Christine, A., Northrop-Clewes, A., and David, I.T. (2006). Monitoring micronutrient in cigarette smokers. Science direct 377: (pp 14-38).

12. Christine, A.N. and David, I.F. (2007). Monitoring micronutrient in cigarette smokers. Clinica Chimical Acta, 377: (pp 14-38).

13. Chui, Y.W., Chuang, H.Y., Huang, M.C., Wu, M.T., Lui, H.W., and Huang, C.T. (2009). Comparison of plasma antioxidant levels and related metabolic parameters between smokers and non-smokers: Kaohsiung J Med Sci, 25(8); (pp 423-30).

14. Cooke, R. W. (1991). Smoking, Intra-Uterine Growth Retardation and Sudden Infant Death Syndrome. Intl J of Epid, 27(2): (pp 238-4).
15. Cross, C.E., and Halliwell, B. (1993). Nutrition and human disease; how much extra vitamin $\mathrm{C}$ might smokers need? Lancer 341, (pp 1091).

16. Eduardu, D., Paolo, B.D., Maria, Julio, C.C., Alvano, R., and Luis, O. (1999). Dietary antioxidants and lung cancer risk; A case control study in Uruguay. Nutrition and cancer center, 34(1), (pp 100-10).

17. Eiserich, J.P. Van der, V.A., Handelman, G.J., Halliwell, B., and Cross, C.E. (1995). Dietary antioxidants and cigarette smokes-induced biomolecular damage: a complex interaction. Am J Clin Nutr, 62: (pp 36-55).

18. Flemming, N., Bo, B.M., Jesper, B.N., Helle, R.A., and Phillippe, G. (1997). Plasma Malondialdehyde as a biomarker for oxidative stress: reference intervaland effect of life-style factors. Clinical chemistry 43(7): (pp 1209-14).

19. Gades, N.M., Nehra, A., and Jacobson, D.J. (2005). Association between smoking and erectile dysfunction: a population-based study. Am J Epidemiol, 161: (pp 346-51).

20. Galan, P., Veteri, F.E and Bertrais, S. (2005). Serum concentration of betacarotene, vitamin $\mathrm{C}$ and $\mathrm{E}$, zinc and seleniumare influenced by sex, age, diet, smoking status, alcohol consumption and corpulence in a general French adult population. Eur J Clin nutr 59: (pp 1181-90).

21. Gandhi, K.K., Foulds, J., and Steinberg, M.B. (2009). Lower quit rates among Africans American and Latino menthol cigarette smokers at a tobacco treatment clinic. Int J. Clin Pract, 63(3): (pp 360-367).

22. Gboyega, E. A., Adesegun, J. K., Chikezie, U. E. (2013). Tobacco smoking and awarenesscessation products in the university community: Academic journal: 5(8), (pp 351-6).

23. Gey, K.F. (1992). Vitamin E and other essential antioxidants regarding coronary heart disease: risk assessment studies. Epidemiological basis of antioxidants hypothesis of cardiovascular disease. In Vitamin $E$ in health and disease, 20: (pp 589).

24. Greg, K.N.D. (2003). The interaction of cigarette smoking and antioxidants: part III, Ascorbic acid. Alterm Med Rev, 8(1), (pp 43-54).

25. Hartman, P.E. (1983). Assay of Malondialdehyde in the serum. Science, 5(4): (pp 603-7).

26. Hauwa'u, A. B., Abdullahi, D., and Gaddafi, I. D. (.2017). Effects of Cigarette Smoking on Lipid Peroxidation and Serum Antioxidant Vitamins. IOSR Journal of Pharmacy and 


\section{International Journal of Engineering Applied Sciences and Technology, 2019 \\ Vol. 4, Issue 6, ISSN No. 2455-2143, Pages 240-248 \\ Published Online October 2019 in IJEAST (http://www.ijeast.com)}

Biological Sciences (IOSR-JPBS) Volume 12, Issue 2 Ver. IV (pp 40-44).

27. Heinecke, J., Li, W., and Mueller, D.M. (1994). Cholesterol chlorohydrins synthesis by the myeloperoxidase-hydrogen peroxide-chrolide system: Potential markers for lipoproteins. Biochem, 33:10, (pp 127-36).

28. Henderson, J.P., Byun, J., and Heineck, J.W. (1999). Molecular chlorine generated by the myeloperoxidase-hydrogen peroxide-chloride system of phagocyte produces 5-chlorocytosine in bacterial RNA. J. Biol. Chem, 274:33, (pp 440-8).

29. Iain, L., Chappel, C., and Mathew, J.B. (2007). The role of relative oxygen and antioxidant species in periodontal tissue destruction. Periodontol 2000, 43: (pp 160-232).

30. Jackshaw, A., Rodock, C., and Boniface, S. (2011). Maternal smoking in pregnancy and birth defects. Hum Reprod Update, 17(5); (pp 589604).

31. Johnson, E.J., Qin, J., Krinsky, N.I., and Russel, R.M. (1997). Beta-carotene isomers in human serum, breast milk and buccal mucosa cells after continuous oral doses of all- trans and 9-cis betacarotene, J. Nutr. 127. (pp 1993-9).

32. Kelly, G. (2002). The interaction of cigarette smoking and antioxidant. Part II: alphatocopherol. Alten Med Rev 7: (pp 500-11).

33. Kim, Y., Shin, A., and Gwack, J. (2007). Cigarette smoking and gastric cancer risk in a community-based cohort study in Korea. Prev Med Pub health, 40: (pp 467-74).

34. Latimer G.W. Jr. (2007). Eggs and egg products: AOAC international official method, 18th ed., AOAC international Gesthesbough; chapter, 34: (pp 01-02).

35. Levenson, R.W. (2003). Autonomic specificity and emotion. In: Davidson RJ, Scherer KR, Goldsmith HH, editors. Handbook of affective sciences. New York: Oxford University Press; (pp 212-224).

36. Mezzetti, A., Lapnna, D., Pierdomenico, S.D., Calafiore, A.M., Constantini, F., Riario-Sforza, G., Imbastaro, T., Neri, M., and Cuccurollo, F. (1995). Vitamin E, C and lipid peroxidation in plasma and arterial tissues of smokers and nonsmokers Artherosclerosis, 112: (pp 91-9).

37. Maod, G., and Solom, D.H. (1995). The Chemistry of Free Radical Polymerization. Pergamon Press: Oxford.

38. Morrow, J.D., Frei, B., Longmire, A.W., Gaziano, J.M., Lynch, S.M., Shyr. Y., Stauss, W.E., Oates, J.A., and Roberts, L.J. (1995).
Increase in circulating products of lipid peroxidation (F2-Isoprostanes) in smokers. $N$. Engl. J. Med., 332: (pp 1198-203).

39. Ojima, F., Sakamoto, H., Ishinguro, Y., and Terao, J. (1993). Consumption of carotenoids in photosensitized oxidation of human plasma lowdensity lipoprotein. Free radic. Biol. Med., 15: (pp 377-384).

40. Palanisamy, P., Ganesan, S., and Palanisamy, C. (2009). Effects of chronic smoking on lipid peroxidation and antioxidant status in gastric carcinoma patients. Indian Journal of gastroentrol, 28 (2), (pp 65-7).

41. Pryor, W.A., and Stone, K. (1993). Oxidants in cigarette smoke. Radicals, hydrogen peroxide, peroxynitrate, and peroxynitrite. Ann $N Y$ Acadsci, 686: (pp 12-28).

42. Reejamol, M.K., and Swaminathan, M. (2013). Comparative study on the antioxidants levels in smokers and non-smokers with chronic perodentitis. Indian Journal of dentistry 4. (pp 67-71).

43. Satyanarayana, U., and Chakrapani, U. (2006). Biochemistry 3rd edition, Book and allied (p) Ltd. India, (pp 100-170).

44. Thum, M.J. (2013). 50-Years Trends in Smoking-related Mortality in the United States. New England Journal of Medicine, 468: (pp 4).

45. Vardavas, C.I., Anagnostopoulos, N., and Kougias, M. (2012). Short-term pulmonary effects of using an electronic cigarette: impact on respiratory flow resistance, impedance, and exhaled nitric oxide. Chest, 141(6): (pp 1400-6).

46. Wallstrom, P., Wirfalt, E., and Pert, H.L. (2000). Serum concentration of $\beta$ - carotene and $\alpha$ tocopherol are associated with diet, smoking and central adiposity: The American Journal of Clinical Nutrition, 73: (pp 777-85).

47. Walmsley, C.M., Bates, C.J., Prentice, A., and Cole, T.J. (1994). Relationship between cigarette smoking and nutrient intakes and blood status indices of older people living in Uk: further analysis of data from the National Diet and Nutrition survey of people aged 65 years and over.

48. World Health Organization (WHO) (2002). The World Health Report - reducing risks, promoting health life. Geneva, Switzerland. 